\title{
VARIABILIDADE GENÉTICA DE ACESSOS SILVESTRES E COMERCIAIS DE Passiflora edulis Sims. COM BASE EM MARCADORES RAPD ${ }^{1}$
}

GRACIELE BELLON ${ }^{2}$, FÁBIO GELAPE FALEIRO ${ }^{3}$, KEIZE PEREIRA JUNQUEIRA $^{4}$, NILTON TADEU VILELA JUNQUEIRA $^{3}$, ERIVANDACARVALHO DOS SANTOS ${ }^{5}$, MARCELO FIDELES BRAGA ${ }^{3}$, CLÁUDIATEIXEIRA GUIMARÃES ${ }^{6}$

RESUMO - No Cerrado brasileiro, há uma grande diversidade de cores, tamanhos e aromas de frutos em acessos silvestres de $P$. edulis. Estes acessos também são importantes fontes de resistência a doenças, podendo ser incorporados em programas de melhoramento genético do maracujazeiro azedo. Neste trabalho, objetivou-se estimar a variabilidade genética existente em acessos silvestres e comerciais de P. edulis utilizando-se de marcadores RAPD. O DNA genômico de cada acesso foi extraído e amplificado com treze iniciadores decâmeros (OPD-04, OPD-07, OPD-08, OPD-16, OPE-18, OPE-20, OPF-01, OPF-14, OPG-05, OPG-08, OPH-04, OPH-12 e OPH-16) para a obtenção dos marcadores RAPD. Os marcadores obtidos foram convertidos em uma matriz de dados binários, a partir da qual foram estimadas as distâncias genéticas entre os acessos e realizadas análises de agrupamento e de dispersão gráfica. Um total de 187 marcadores foi gerado, sendo que apenas 28 (14,97\%) deles foram monomórficos. As distâncias genéticas entre os 15 acessos de maracujazeiro variaram de 0,091 a 0,496. Os marcadores moleculares demonstraram a alta variabilidade genética dos acessos de P. edulis, sendo que os acessos de frutos amarelos apresentaram maior distanciamento em relação aos de frutos roxos. Menores distâncias genéticas foram verificadas entre os acessos de mesma origem geográfica.

Termos para indexação: maracujá, marcadores moleculares, variabilidade intra-específica

\section{GENETIC VARIABILITY OF WILD AND COMMERCIAL PASSION FRUIT (Passiflora edulis Sims.) ACCESSIONS USING RAPD MARKERS}

\begin{abstract}
There are a great diversity of colors, sizes and aromas of fruits in wild accessions of $P$. edulis in Brazilian Savannah. These accessions are also important resistance sources against illness which can be incorpored in passionfruit breeding programs. In this work, the objetive was to evaluate the genetic variability in wild and commercial $P$. edulis accessions using RAPD markers. The genomic DNA of each accession was extracted and amplified using thirteen decamer primers (OPD-04, OPD-07, OPD-08, OPD-16, OPE18, OPE-20, OPF-01, OPF-14, OPG-05, OPG-08, OPH-04, OPH-12 and OPH-16) to obtain RAPD markers. These markers were transformed in binary matrix data to estimate genetic distances among accessions and to perform cluster and graphical dispersion analysis. A total of 187 markers were generated, and only $28(14.97 \%)$ of them were monomorphic. The genetic distances among the 15 P. edulis accessions varied from 0.091 to 0.496 . The molecular markers demonstrated the high genetic variability of the wild and commercial $P$. edulis accessions. The accessions with yellow fruits presented greater genetic distances in relation to the accessions with purple fruits. Lower genetic distances were verified among the accesses of the same geographical origin.
\end{abstract}

Index terms: passionfruit, molecular markers, intraespecific variability.

\section{INTRODUÇÃO}

O maracujazeiro é uma planta com ampla variabilidade genética a ser conhecida, caracterizada, protegida, conservada e convenientemente utilizada comercialmente ou em programas de melhoramento genético (Faleiro et al., 2005a). Segundo Vanderplank (1996), a família Passifloraceae é formada por 18 gêneros e 630 espécies, sendo o gênero Passiflora o mais importante economicamente. Estima-se que esse gênero seja composto por 465 espécies, das quais 150 a 200 são originárias do Brasil. A espécie mais cultivada é $P$. edulis, sendo o grupo amarelo predominante no mercado interno e o grupo roxo mais apreciado no exterior.

Devido a sua importância econômica, a espécie $P$. edulis tem sido alvo de diversos programas de melhoramento no Brasil e na Austrália. No Cerrado brasileiro, há uma grande variedade de cores, tamanhos e aromas de frutos em acessos silvestres de P. edulis, havendo a possibilidade de incorporação destes em programas de melhoramento genético do maracujazeiro azedo.

Por se tratar de uma espécie semiperene, o estudo de diversidade genética em Passiflora spp. requer tempo e sofre grande influência do ambiente. Neste caso, o uso de marcadores moleculares é uma ferramenta valiosa, por permitir um rápido, preciso e acurado estudo da variabilidade existente, detectando

(Trabalho 138-2006) Recebido:em 12-09-2006. Aceito para publicação em 13-02-2007.

2 Eng. Agr. Mestranda em Ciências Agrárias/Universidade de Brasília, Câmpus Universitário Darcy Ribeiro, 70910-900 Brasília-DF. Endereço eletrônico: bellon@cpac.embrapa.br

${ }^{3}$ Pesquisador da Embrapa Cerrados, BR 020, Km 18, Caixa Postal 08223, 73010-970 Planaltina- DF. Endereço eletrônico: ffaleiro@cpac.embrapa.br, junqueir@cpac.embrapa.br, fideles@cpac.embrapa.br

${ }^{4}$ Eng. Agr. Mestranda em Fitotecnia/Universidade Federal de Lavras, Caixa Postal 3037, 37200-000 Lavras- MG. Endereço eletrônico: keize@ ufla.br

${ }^{5}$ Estagiária da Embrapa Cerrados, BR 020, Km 18, Caixa Postal 08223, 73010-970 Planaltina- DF.

${ }_{6}$ Pesquisadora da Embrapa Milho e Sorgo, Rod. MG 424 Km 65, Caixa Postal 151, 35701-970 Sete Lagoas- MG. Endereço eletrônico: claudia@cnpms.embrapa.br 
as variações diretamente no DNA. No presente trabalho, objetivou-se analisar a variabilidade genética de acessos silvestres e comerciais de maracujazeiro azedo (Passiflora edulis Sims.), utilizando-se de marcadores moleculares RAPD.

\section{MATERIAL E MÉTODOS}

O trabalho foi realizado no Laboratório de Genética e Biologia Molecular da Embrapa Cerrados, sendo analisados 11 acessos silvestres e quatro acessos comerciais de Passiflora edulis Sims., dos quais três foram introduzidos da Austrália (Tabela 1).

O DNA genômico de cada acesso foi extraído utilizando o método do CTAB, com modificações (Faleiro et al., 2003). Amostras de DNA de cada acesso foram amplificadas pela técnica de RAPD. As reações de amplificação foram feitas em um volume total de $13 \mathrm{uL}$, contendo Tris- $\mathrm{HCl} 10 \mathrm{mM}$ (pH 8,3), $\mathrm{KCl} 50 \mathrm{mM}$, $\mathrm{MgCl} 23 \mathrm{mM}, 100 \mathrm{uM}$ de cada um dos desoxiribonucleotídios (dATP, dTTP, dGTP e dCTP), 0,4 uM de um iniciador (Operon Technologies Inc., Alameda, CA, EUA), uma unidade da enzima Taq polimerase e, aproximadamente, $15 \mathrm{ng}$ de DNA.

Para a obtenção dos marcadores RAPD, foram utilizados 13 iniciadores decâmeros: OPD-04, OPD-07, OPD-08, OPD-16, OPE-18, OPE-20, OPF-01, OPF-14, OPG-05, OPG-08, OPH-04, OPH$12 \mathrm{e}$ OPH-16. As amplificações foram efetuadas em termociclador programado para 40 ciclos, cada um constituído pela seguinte seqüência: 15 segundos a $94{ }^{\circ} \mathrm{C}, 30$ segundos a $35{ }^{\circ} \mathrm{C}$ e 90 segundos a $72{ }^{\circ} \mathrm{C}$. Após os 40 ciclos, foi feita uma etapa de extensão final de seis minutos a $72^{\circ} \mathrm{C}$, e, finalmente, a temperatura foi reduzida para $4^{\circ} \mathrm{C}$. Após a amplificação, foram adicionados, a cada amostra, $3 \mathrm{uL}$ de uma mistura de azul de bromofenol $(0,25 \%)$ e glicerol (60\%) em água. As amostras foram aplicadas em gel de agarose $(1,2 \%)$, corado com brometo de etídio $(0,2 \mathrm{ug} / \mathrm{mL})$, submerso em tampão TBE (Tris-Borato 90 mM, EDTA 1 mM). A separação eletroforética foi de, aproximadamente, quatro horas, a 90 volts. Ao término da corrida, os géis foram fotografados sob luz ultravioleta.

Os marcadores RAPD gerados foram convertidos em uma matriz de dados binários, a partir da qual foram estimadas distâncias genéticas entre cada par de acesso, com base no complemento do coeficiente de similaridade de Nei \& Li (1979), utilizando-se do Programa Genes (Cruz, 1997). A matriz de distâncias genéticas foi utilizada para realizar a análise de agrupamento por meio de dendrograma, utilizando-se do método UPGMA (Unweighted Pair Group Method with Arithmetic Mean), como critério de agrupamento, e a dispersão gráfica baseada em escalas multidimensionais, usando o método das coordenadas principais, com auxílio do Programa SAS e Statistica (Statsoft Inc., 1999).

\section{RESULTADOS E DISCUSSÃO}

Os 13 iniciadores decâmeros geraram um total de 187 marcadores RAPD, perfazendo uma média de 14,4 marcadores por iniciador. Dos 187 marcadores, apenas 28 (14,97\%) foram monomórficos (Tabela 2). A alta média de marcadores por iniciador e a baixa porcentagem de marcadores monomórficos evidenciam a alta variabilidade genética intra-específica dos acessos analisados.

Alguns autores já haviam observado variabilidade genética expressiva em diferentes acessos de uma mesma espécie de Passiflora. Bellon et al. (2005) observaram grande variabilidade intra-específica entre acessos comerciais e silvestres de $P$. alata. Junqueira et al. (2005), trabalhando com acessos de $P$. nitida, verificaram uma alta variabilidade, especialmente quando se compararam acessos de procedências diferentes.

Por outro lado, estudos realizados por Pio Viana et al. (2003) e Faleiro et al. (2005b), utilizando-se de diferentes acessos da espécie comercial $P$. edulis amarelo, não mostraram expressiva variabilidade genética entre esses materiais, indicando um possível estreitamento da base genética entre as cultivares comerciais. Estudos preliminares realizados por Junqueira et al. (2003) mostraram que essa baixa variabilidade entre as cultivares atuais de maracujazeiro- amarelo tem contribuído para a redução da resistência a doenças nas mesmas. Faleiro et al. (2004) ressaltam a importância do uso de espécies nativas de maracujá para programas de melhoramento genético visando à ampliação da variabilidade genética, principalmente para a resistência a doenças.

As distâncias genéticas entre os 15 acessos de maracujazeiro variaram entre 0,09 e 0,50 (Tabela 3). A menor distância genética foi de 0,09 obtida entre os acessos 96A (11) e G25 (12) de P. edulis procedentes da Austrália, seguida por 0,11 observada entre os acessos Cinza P1 (1) e Cinza P4 (4) procedentes de Taguatinga-TO. A maior distância genética foi de 0,50 observada entre o acesso silvestre de $P$. edulis Cinza P2 (2) e o P. edulis amarelo comercial GA2 (15). Faleiro et al. (2005b), estudando acessos comerciais e um acesso silvestre de $P$. edulis amarelo, também verificaram altas distâncias genéticas entre o acesso silvestre e os comerciais 'Gigante Amarelo' e 'EC-3-O', com valores de 0,473 e 0,474 , respectivamente.

A análise de agrupamento, realizada com base nas distâncias genéticas, permitiu subdividir os 15 acessos em, pelo menos, 7 grupos de similaridade genética a uma distância genética relativa de 0,26 (Figura 1). As distâncias entre os acessos e a distribuição dos mesmos nos grupos de similaridade podem ser também observadas no gráfico de dispersão (Figura 2). Os dois maiores grupos foram formados pelos acessos de P. edulis Cinza

TABELA 1 - Acessos de Passiflora edulis Sims. analisados.

\begin{tabular}{clcll}
\hline $\mathbf{N}^{\mathbf{0}}$ & \multicolumn{1}{c}{ Acesso } & Cor do Fruto & \multicolumn{1}{c}{ Procedência } & \multicolumn{1}{c}{ Código } \\
\hline 1 & Cinza P1 & Roxo Acinzentado & Taguatinga-TO & CPAC MJ-21-05 \\
2 & Cinza P2 & Roxo Acinzentado & Taguatinga- TO & CPAC MJ-21-06 \\
3 & Cinza P3 & Roxo Acinzentado & Taguatinga- TO & CPAC MJ-21-07 \\
4 & Cinza P4 & Roxo Acinzentado & Taguatinga- TO & CPAC MJ-21-08 \\
5 & Itumirim & Roxo & Itumirim- MG & CPAC MJ-21-01 \\
6 & Ribeirão Vermelho & Roxo & Ribeirão Vermelho- MG & CPAC MJ-21-02 \\
7 & Pintado & Roxo & Arinos- MG & CPAC MJ-21-04 \\
8 & Vermelho & Roxo Avermelhado & São Lourenço- MG & CPAC MJ-21-03 \\
9 & Roxo Jaboticaba & Roxo & Cachoeira Paulista- SP & CPAC MJ-21-10 \\
10 & Roxo Australiano* & Roxo & Austrália & CPAC MJ-M-14 \\
11 & Roxo 96A* & Roxo & Austrália & CPAC MJ-21-11 \\
12 & Roxo G25* & Roxo & Austrália & CPAC MJ-21-12 \\
13 & Amarelo MG & Amarelo & Perdões- MG & CPAC MJ-36-01 \\
14 & Amarelo TO & Amarelo & Taguatinga-TO & CPAC MJ-36-02 \\
15 & GA2* & Amarelo & Embrapa Cerrados- DF & CPAC MJ-M-01 \\
\hline A Acessos comerciais & & &
\end{tabular}

Rev. Bras. Frutic., Jaboticabal - SP, v. 29, n. 1, p. 124-127, Abril 2007 
TABELA 2 - Iniciadores utilizados para a obtenção dos marcadores RAPD, com os respectivos números de bandas polimórficas e monomórficas.

\begin{tabular}{cccc}
\hline Iniciadores & Seqüência $5^{\prime} \rightarrow 3^{\prime}$ & $\begin{array}{c}\mathrm{N}^{\circ} \text { de bandas } \\
\text { polimórficas }\end{array}$ & $\begin{array}{c}\mathrm{N}^{\circ} \text { de bandas } \\
\text { monomórficas }\end{array}$ \\
\hline OPD-04 & TCTGGTGAGG & 3 & 2 \\
OPD-07 & TTGGCACGGG & 6 & 2 \\
OPD-08 & GTGTGCCCCA & 7 & 2 \\
OPD-16 & AGGGCGTAAG & 7 & 1 \\
OPE-18 & GGACTGCAGA & 2 & 5 \\
OPE-20 & AACGGTGACC & 4 & 5 \\
OPF-01 & ACGGATCCTG & 19 & 1 \\
OPF-14 & TGCTGCAGGT & 23 & 2 \\
OPG-05 & CTGAGACGGA & 28 & 0 \\
OPG-08 & TCACGTCCAC & 21 & 1 \\
OPH-04 & GGAAGTCGCC & 13 & 1 \\
OPH-12 & ACGCGCATGT & 12 & 3 \\
OPH-16 & TCTCAGCTGG & 14 & 3 \\
\hline TOTAL & & 159 & 28 \\
\hline
\end{tabular}

TABELA 3 - Matriz de distâncias entre 15 acessos de maracujazeiro, baseada em 187 marcadores RAPD.
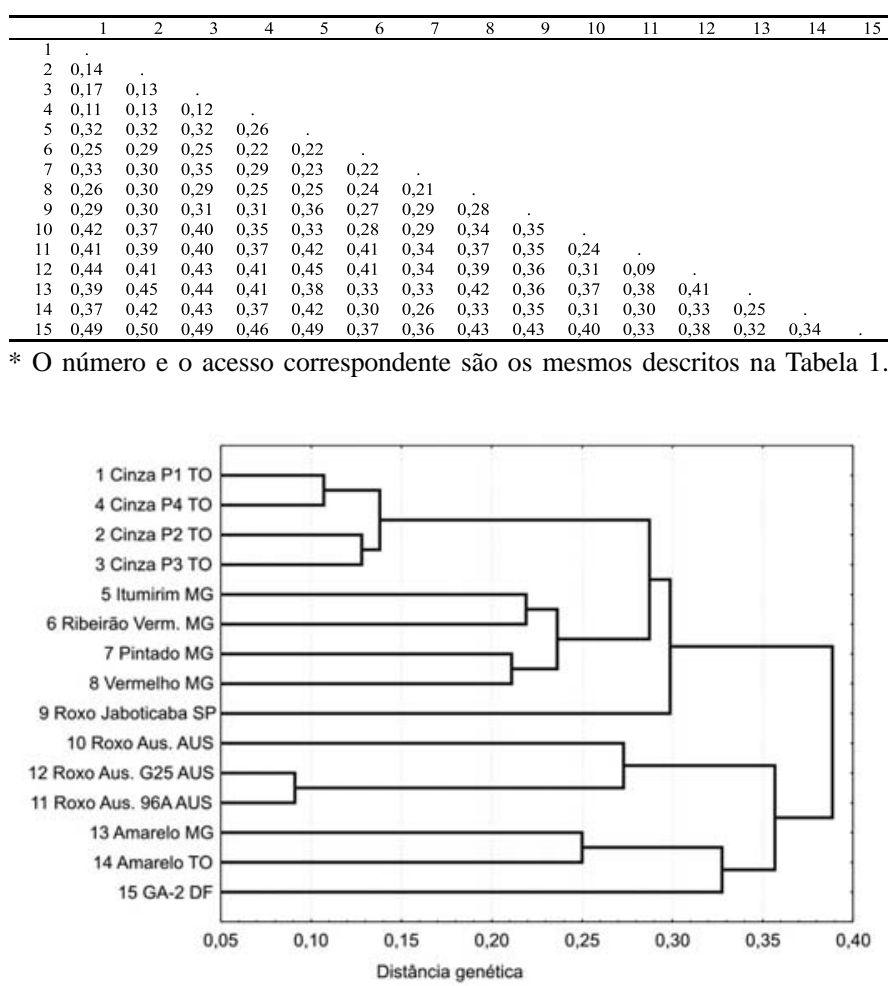

FIGURA 1 - Análise de agrupamento de 15 acessos de maracujazeiro com base na matriz de distâncias genéticas calculadas, utilizando-se de 187 marcadores RAPD. O método do UPGMA foi utilizado como critério de agrupamento.

P1, P2, P3 e P4 (1; 2; 3 e 4) procedentes de Tocantins e pelos acessos 5; 6; 7 e 8 procedentes de Minas Gerais. Dentro do primeiro grupo, pode-se verificar maior similaridade entre os acessos Cinza P1 (1) e P4 (4). No segundo grupo, a menor distância genética foi observada entre $P$. edulis Pintado (7) e $P$. edulis Vermelho (8). Com base na análise do dendrograma, pôde-se

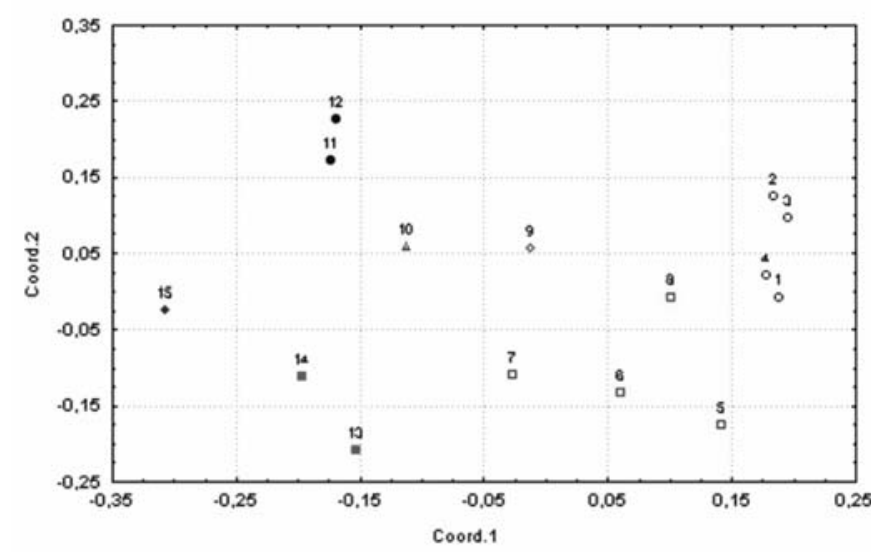

FIGURA 2 - Dispersão gráfica dos 15 acessos de maracujazeiro com base na matriz de distâncias genéticas calculadas, utilizando-se de 187 marcadores RAPD. Os números correspondem aos acessos da Tabela 1. Acessos com o mesmo símbolo formaram grupos de similaridade na Figura 1.

observar uma tendência de agrupamento entre aqueles acessos procedentes da mesma região geográfica, considerando tanto os diferentes estados brasileiros (Minas Gerais e Tocantins) quanto países (Austrália).

Outra tendência observada foi a separação dos acessos de frutos amarelos em relação aos de frutos roxos nativos do Brasil e introduzidos da Austrália, considerando o ponto de corte do dendrograma a uma distância de 0,35 . Tal separação indica que, apesar de taxonomicamente pertencerem à mesma espécie, os acessos de frutos roxos e de frutos amarelados são geneticamente distintos. Portanto, torna-se conveniente acrescentar à sua nomenclatura uma denominação referente ao grupo ao qual pertence determinado acesso, como Passiflora edulis grupo edulis, referindo-se ao material de casca arroxeada e Passiflora edulis grupo flavicarpa, referindo-se ao material de casca amarela. Tal possibilidade foi relatada por Bernacci et al. (2005), embora as terminologias $P$. edulis f. edulis e P. edulis f. flavicarpa sejam muito utilizadas e mundialmente aceitas na redação científica.

Ainda, houve uma clara distinção dos acessos comerciais com relação aos demais acessos silvestres, uma vez que as cultivares Roxos da Austrália e Amarelo Comercial GA-2 não foram agrupadas com qualquer outro acesso a uma distância de 0,26. A mesma tendência foi verificada por Faleiro et al. (2004). Tal fato se deve aos materiais selecionados em programas de melhoramento possuírem características definidas pelo mercado, principalmente em relação ao maior tamanho e uniformidade de frutos, as quais não são típicas dos acessos silvestres.

A grande variabilidade genética entre os acessos de $P$. edulis evidencia a ampla base genética da espécie, abrindo boas perspectivas para o uso dos acessos silvestres em programas de melhoramento do maracujazeiro azedo. Sendo $P$. edulis a principal espécie de uso comercial dentro do gênero Passiflora, a utilização dos acessos silvestres em tais programas seria facilitada considerando a provável compatibilidade genética com os acessos comerciais. Além do uso em programas de melhoramento, 
os acessos silvestres também são novas alternativas para o mercado de consumo in natura, ornamental e medicinal. Entretanto, o potencial de cada acesso silvestre deve ser respaldado em estudos mais apurados referentes aos aspectos agrônomicos e de herança das diferentes características de interesse.

\section{CONCLUSÕES}

1. Os acessos de P. edulis apresentaram grande variabilidade genética, considerando os acessos silvestres e comerciais.

2. Maior similaridade genética foi verificada entre os acessos de mesma origem geográfica.

3. Os acessos com frutos amarelos apresentaram maior distanciamento em relação aos com frutos roxos nativos do Brasil e introduzidos da Austrália.

4. A grande variabilidade genética entre os acessos de $P$. edulis abre boas perspectivas para o uso dos acessos silvestres em programas de melhoramento do maracujazeiro azedo ou como alternativas para o mercado de consumo in natura, ornamental e medicinal.

\section{REFERÊNCIAS}

BELLON, G.; FALEIRO, F.G.; JUNQUEIRA, K.P.; PAULA, M.S.; BRAGA, M.F.; JUNQUEIRA, N.T.V.; PEIXOTO, J.R. Diversidade genética de acessos comerciais e silvestres de maracujazeiro-doce com base nos marcadores RAPD. In: FALEIRO, F.G.; JUNQUEIRA, N.T.V.; BRAGA, M.F. (Ed.). REUNIÃO TÉCNICA DE PESQUISAS EM MARACUJAZEIRO, 4., 2005. Planaltina Distrito Federal: Embrapa Cerrados, 2005. p.118-121.

BERNACCI, L.C.; MELETTI, L.M.M.; SCOTT, M.D.S.; PASSOS, I.R.S. Espécies de maracujá: Caracterização e conservação da biodiversidade . In: FALEIRO, F.G.; JUNQUEIRA, N.T.V.; BRAGA, M.F.(Ed.). Maracujá: germoplasma e melhoramento genético. Planaltina Distrito Federal: Embrapa Cerrados, 2005. p.559-586.

CRUZ, C.D. Programa Genes: aplicativo computacional em genética e estatística. Viçosa: UFV, 1997. 442p.

FALEIRO, F.G.; FALEIRO, A.S.G.; CORDEIRO, M.C.R., KARIA, C.T. Metodologia para operacionalizar a extração de DNA de espécies nativas do cerrado. Planaltina: Embrapa Cerrados, 2003. 6p. (Comunicado Técnico, 92).

FALEIRO, F.G;; JUNQUEIRA, N.T.V.; BELLON, G.; BORGES, T.A.; ANJOS, J.R.N.; PEIXOTO, J.R.; BRAGA, M.F.; SANTOS, D.G. Diversidade genética de espécies silvestres de maracujazeiro com resistência a múltiplas doenças com base em marcadores RAPD. Fitopatologia Brasileira, Brasília, v. 29, supl, p. S325, 2004.

FALEIRO, F.G.; JUNQUEIRA, N.T.V.; BRAGA, M.F. Germoplasma e melhoramento genético do maracujazeiro- Desafios da pesquisa. In: FALEIRO, F.G.; JUNQUEIRA, N.T.V.; BRAGA, M.F.(Ed.). Maracujá: germoplasma e melhoramento genético. Planaltina Distrito Federal: Embrapa Cerrados, 2005a. p.187210.
FALEIRO, F.G.; JUNQUEIRA, N.T.V.; BRAGA, M.F.; BELLON, G.; PEIXOTO, J.R. Diversidade genética de variedades comerciais de maracujazeiro-azedo com base em marcadores RAPD. In: REUNIÃ̃O TÉCNICA DE PESQUISAS EM MARACUJAZEIRO, 4., Planaltina, DF: Embrapa Cerrados, 2005b. p.105-109.

JUNQUEIRA, K.P.; FALEIRO, F.G.; RAMOS, J.D.; BELLON, G.; PAULA, M.S.; JUNQUEIRA, N.T.V.; BRAGA, M.F. Variabilidade genética de acessos de maracujá-suspiro (Passiflora nitida Kunth.) com base nos marcadores moleculares. In: REUNIÃO TÉCNICA DE PESQUISAS EM MARACUJAZEIRO, 4., 2005. Planaltina, DF: Embrapa Cerrados, 2005. p.122-127.

JUNQUEIRA, NT.V.; ANJOS, J.R.N.; SILVA, A.P.O.; CHAVE, R.C.; GOMES, A.C. Reação às doenças e produtividade de onze cultivares de maracujazeiro-azedo cultivadas sem agrotóxico. Pesquisa Agropecuária Brasileira, Brasília, v.38, n.8, p. 1005-1010, 2003.

NEI, M.; LI, W.H. Mathematical model for studying genetic variation in terms of restriction endonucleases. Proceedings of the National Academy of Science, Missouli, v.76, p. 52695273, 1979.

PIO VIANA, A.; PEREIRA, T.N.S.; PEREIRA, M.G.; SOUZA, M.M.; MALDONADO, F.; AMARAL JÚNIOR, A.T. Diversidade em maracujazeiro amarelo (Passiflora edulis $\mathrm{f}$. flavicarpa) e Passiflora spp. por marcadores RAPD. Revista Brasileira de Fruticultura, Jaboticabal, v.25, p.489-493. 2003.

STATSOFT. Statistica for Windows: [Computer program manual]. Tulsa, OK: StatSoft, 1999.

VANDERPLANK, J. Passion flowers. Massachusetts: Press, 1996. 224p. 